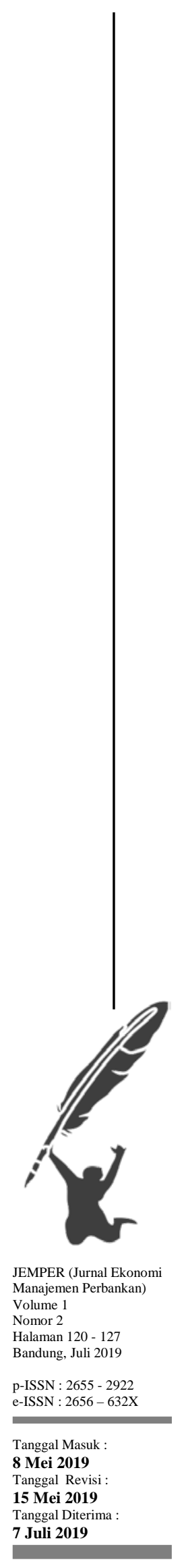

JEMPER(Jurnal Ekonomi Manajemen Perbankan)

http://jurnal.usbypkp.ac.id/index.php/jemper

\title{
PENGARUH KUALITAS PELAYANAN AKADEMIK DAN COSTUMER RELATIONSHIP MANAGEMENT TERHADAP KEPUASAN MAHASISWA REGULER PAGI UNIVERSITAS SANGGA BUANA YPKP BANDUNG
}

\author{
Anissa Primafidyanti ${ }^{1}$ \\ Universitas Sangga Buana YPKP Bandung \\ anissaprima10@gmail.com \\ Sumeidi Kadarisman ${ }^{2}$ \\ Universitas Sangga Buana YPKP Bandung \\ sumeidi1958@gmail.com
}

\begin{abstract}
This research aims to detremine, describe and analyze the effects of academic service and customer relationship management on student satisfaction. The method used is decriptive verificative with quantitative approach. Sample taking used cluster proportionare random sampling of 92 people. Data analysis showed that $r 2$ value is 0,486 . Based on the test results the partial hypotesis for the quality of thitung academic service, the value of thitung is 3,410 while ttabel's value is 1,986 which means that the quality of academic service has a significant impact on student satisfaction. thitung value for customer relationship management is 3,509 while ttabel's value is 1,986 which means that customer relationship management has a significant impact on student satisfaction. Based on simultaneously hypotesis Fhitung's value is 42,129 while Ftabel's value is 1,986 which means that simultaneously there is a significant effect between the quality of academic service and customer relationship management approach to student satisfaction.

Keywords: Quality Of Academic Service, Customer Relationship Management, Student Satisfaction
\end{abstract}

\begin{abstract}
Abstrak
Penelitian ini bertujuan untuk mengetahui, mendeskripsikan serta menganalisis pengaruh kualitas pelayanan akademik dan costumer relationship management terhadap kepuasan mahasiswa. Metode menggunakan deskriptif verifikatif dengan pendekatan kuantitatif. Pengambilan sampel menggunakan Cluster Propotionate Random Sampling sebanyak 92 orang. Hasil analisis data menunjukkan bahwa nilai r2 yang diperoleh sebesar 0,486 yang berarti bahwa variasi pengaruh kualitas pelayanan akademik dan costumer relationship management terhadap kepuasan mahasiswa hanya sebesar 48,6\%. Berdasarkan hasil uji hipotesis parsial untuk kualitas pelayanan akademik nilai thitung sebesar 3,410 sedangkan nilai ttabel sebesar 1,986 yang berarti bahwa kualitas pelayanan akademik berpengaruh signifikan terhadap kepuasan mahasiswa. Nilai thitung untuk costumer relationship management sebesar 3,509 sedangkan nilai ttabel sebesar 1,986 yang berarti bahwa costumer relationship management berpengaruh signifikan terhadap kepuasan mahasiswa. Berdasarkan uji hipotesis simultan nilai Fhitung sebesar 42,129 sedangkan nilai Ftabel sebesar 1,986 yang berarti secara simultan terdapat pengaruh yang signifikan antara kualitas pelayanan akademik dan costumer relationship management terhadap kepuasan mahasiswa.
\end{abstract}

Kata kunci : Kualitas Pelayanan Akademik, CRM, Kepuasan Mahasiswa 


\section{PENDAHULUAN}

Kualitas pelayanan dalam perusahaan jasa bukan lagi menjadi bagian dari strategi pemasaran melainkan menjadi sebuah keharusan yang dimiliki oleh perusahaan jasa melihat pentingnya penilaian dari pelanggan atas kualitas pelayanan yang ditawarkan. Selain kualitas pelayanan dan jasa yang ditawarkan dalam dunia pendidikan, penting juga untuk memperhatikan bagaimana lembaga pendidikan menjalin hubungan baik dengan seluruh pihak yang terkait di dalam lembaga pendidikan tersebut.

Salah satu universitas swasta yang berada di Kota Bandung yaitu Universitas Sangga Buana Yayasan Keuangan Pendidikan dan Perbankan (YPKP). Selama menjalankan tugas sebagai lembaga pendidikan, Universitas Sangga Buana YPKP telah melakukan banyak sekali perubahan yang ditujukan bagi mahasiswa agar lebih merasa nyaman dalam melakukan perkuliahan seperti penambahan sarana dan prasarana ataupun pembaruan sarana dan prasarana yang telah ada. Akan tetapi, dalam pelaksanaan peningkatan kualitas pelayanan yang dilakukan tidak berbanding lurus dengan apa yang diharapkan oleh mahasiswa dan membuat tingkat kepuasan yang dirasakan menurun. Hal ini dibuktikan dengan adanya keluhan yang dirasakan mahasiswa mengenai kualitas pelayanan dan kurangnya hubungan yang baik antara universitas dengan mahasiswa.

Berbagai keluhan yang dirasakan mahasiswa tersebut harus dibuktikan agar penulis bisa menganalisis seberapa besar tingkat kepuasan yang dirasakan oleh mahasiswa, maka itu penulis melakukan pra survey kepada mahasiswa reguler pagi Universitas Sangga Buana YPKP sebanyak 33 orang responden yang dibagi ke setiap fakultas mencakup angkatan 2015 hingga angkatan 2017. Setelah dilakukan pra survey dengan mengajukan beberapa pernyataan tentang kualitas pelayanan, CRM dan kepuasan didapatkan hasil akhir bahwa mahasiswa reguler pagi Universitas Sangga Buana YPKP masih merasa kurang puas dengan kualitas pelayanan dan penerapan Costumer relationship management yang dilakukan.

Berdasarkan latar belakang dan hasil pra survey diatas, penulis tertarik untuk melakukan penelitian dengan judul "Pengaruh Kualitas Pelayanan Dan Costumer Relationship Management (CRM) Terhadap Kepuasan Mahasiswa Reguler Pagi Universitas Sangga Buana YPKP Bandung”

\section{LITERATUR}

\section{Teori dan Konsep}

Sebagai ilmu pengetahuan yang bersifat universal, manajemen mempunyai peran penting bagi penerapan segala aspek yang terdapat dalam tujuan sebuah lembaga ataupun perusahaan. Bila sebuah perusahaan tidak menerapkan manajemen yang baik, maka perusahaan tersebut akan mengalami kesusahan untuk mencapai kemakmuran. (2015:8):

Menurut Stoner pengertian manajemen yang dikutip dalam T. Hani Handoko

"Manajemen adalah proses perencanaan, pengorganisasian, pengarahan, dan pengawasan usaha-usaha para anggota organisasi dan penggunaan sumber daya-sumber daya organisasi lainnya agar mencapai tujuan organisasi yang telah di tetapkan”.

Pemasaran menurut American Marketing Association dalam Fandy Tjiptono dan Anastasia Diana (2016:3) adalah:

"Aktivitas, serangkaian institusi, dan proses menciptakan, mengkomunikasikan, menyampaikan, dan mempertukarkan tawaran (offerings) yang bernilai bagi pelanggan, klien, mitra, dan masyarakat umum”.

Definisi manajemen pemasaran menurut Subeki Ridhotullah dan Mohammad Jauhar (2015:11) adalah "Suatu rencana kegiatan yang dilakukan oleh perusahaan berdasarkan analisa situasi dan tujuan yang telah ditetapkan”. 
Menurut Nasution (2004:47) yang dikutip dalam Mhd Rusydi (2017:39) menyatakan bahwa "Kualitas pelayanan adalah tingkat keunggulan yang diharapkan dan pengendalian atas tingkat keunggulan tersebut untuk memenuhi keinginan konsumen”.

Kotler (2009:173) dalam Kasmir (2017:1) mendefinisikan bahwa:

"CRM sebagai suatu proses mengelola informasi pelanggan yang dilakukan secara hati-hati dan detil yang menyangkut pelanggan secara pribadi dan hal-hal yang berkaitan erat dengan pelanggan (touch points) dengan tujuan untuk memaksimalkan loyalitas mereka”.

Howard \& Sheth (1969) dalam Fandy Tjiptono (2014:353) mengemukakan bahwa "Kepuasan pelanggan adalah situasi kognitif pembeli berkenaan dengan kesepadanan atau ketidaksepadanan antara hasil yang didapatkan dibandingkan dengan pengorbanan yang dilakukan”.

\section{Hubungan antara Kualitas Pelayanan Akademik dengan Kepuasan Mahasiswa}

Dikutip dari Fajar Laksana (2008:96) bahwa kepuasan pelanggan boleh dikatakan sebagai suatu rasio atau perbandingan. Kepuasan akan menjadi tinggi karena pelanggan merasakan bahwa kualitas pelayanan yang diberikan melebihi harapan pelanggan. Sedangkan, jika kepuasan pelanggan menjadi rendah karena pelanggan merasa kualitas pelayanan lebih kecil dari kebutuhan, keinginan, dan harapan pelanggan.

\section{Hubungan antara Customer Relationship Management dengan Kepuasan Mahasiswa} Dikutip dari Hery (2019:86) bahwa memaksimalkan nilai pelanggan berarti membangun hubungan pelanggan jangka panjang. Banyak perusahaan yang mengembangkan ikatan yang lebih kuat dengan palanggan yang disebut dengan relasional pelanggan. Tantangannya adalah bukan menghasikan pelanggan yang puas saja melainkan menghasilkan pelanggan yang senang dan setia menggunakan manajemen hubungan pelanggan yang diterapkan. Jika sebuah perusahaan terlah menerapkan manajemen hubungan pelanggan dengan baik maka dapat dipastikan perusahaan akan meraih kepuasan serta keloyalitasan dari setiap pelanggan.

\section{Kerangka Pemikiran dan Hipotesis}

Perubahan yang dilakukan Universitas Sangga Buana YPKP dalam rangka memenuhi kebutuhan dan keinginan mahasiswa akan pendidikan tidak terlepas dari adanya perkembangan di bidang pelayanan baik akademik maupun non akademik. Selain itu penerapan Costumer relationship management (CRM) yang dilakukan antara pihak uiversitas dengan mahasiswa juga merupakan bagian penting yang menjadi kesatuan untuk tercapainya kepuasan mahasiswa.

Terkait pembuatan suatu karya ilmiah, dibutuhkan sebuah hipotesis yang menjadi dugaan sementara atas fenomena yang terjadi dan sedang diteliti. Syofian Siregar (2014:65) mengutip bahwa para ahli menafsirkan arti hipotesis sebagai "Dugaan terhadap hubungan antara dua variabel atau lebih. Atas dasar definisi tersebut dapat diartikan bahwa hipotesis adalah jawaban atau dugaan sementara yang harus diuji kebenarannya”.

Berdasarkan uraian diatas, maka hipotesis yang diambil dalam penelitian ini adalah :

Hipotesis 1 : Terdapat pengaruh kualitas pelayanan akademik terhadap kepuasan mahasiswa reguler pagi Universitas Sangga Buana YPKP Bandung.

Hipotesis 2 : Terdapat pengaruh Costumer relationship management (CRM) terhadap kepuasan mahasiswa reguler pagi Universitas Sangga Buana YPKP Bandung.

Hipotesis 3 : Terdapat pengaruh kualitas pelayanan dan Costumer relationship management (CRM) terhadap kepuasan mahasiswa reguler pagi Universitas Sangga Buana YPKP Bandung 


\section{METODE PENELITIAN}

\section{Metode dan Jenis Data}

Penelitian ini menggunakan pendekatan secara Kuantitatif. Metode yang digunakan dalam penelitian ini yaitu metode Deskriptif Verifikatif.

\section{Sumber Data}

Terdapat 2 sumber data yang dapat digunakan untuk melakukan sebuah penelitian, yaitu : Primer dan Sekunder. Data Primer yang digunakan dalam penelitian ini adalah data yang diperoleh langsung dari hasil penyebaran kuisioner kepada subjek penelitian penulis. Sedangkan yang menjadi data sekunder pada penelitian ini adalah literatur atau studi kepustakaan baik dari buku, skripsi maupun jurnal yang berkaitan dengan permasalahan yang terdapat pada penelitian ini.

\section{Populasi dan Sampel}

Populasi dalam penelitian ini adalah mahasiswa aktif reguler pagi jenjang Sarjana (S1) dan Diploma (D3) angkatan 2015-2017 yang berjumlah 1086 mahasiswa. Teknik sampling yang digunakan oleh penulis pada penelitian ini adalah teknik Probability Sampling.

Teknik proses penentuan sampel yang digunakan dalam pengambilan sampel pada penelitian ini yaitu Cluster Proportionate Random Sampling. Sampel dalam penelitian ini berjumlah 92 responden.

\section{Teknik Pengumpulan Data}

Teknik pengumpulan data pada penelitian ini menggunakan studi kepustakaan, studi lapangan, dan kuisioner.

\section{Hipotesis}

Dalam penelitian ini menggunakan uji hipotesis secara parsial (Uji t) dan hipotesis secara simultan (Uji F).

\section{HASIL DAN PEMBAHASAN}

\section{Hasil Penelitian}

Karakteristik Responden

Penelitian ini didapat melalui data hasil kuisioner dan menggunakan persepsi dari mahasiswa reguler pagi Universitas Sangga Buana YPKP tentang Kualitas Pelayanan Akademik, Costumer relationship management, serta Kepuasan Mahasiswa. Karakteristik responden yang akan disajikan dalam penelitian ini meliputi jenis kelamin, fakultas, angkatan, serta program studi dari masing-masing responden.

\section{Tanggapan Responden}

Berdasarkan hasil tanggapan resonden mengenai variabel kualitas pelayanan akademik dapat diketahui bahwa terdapat banyak responden yang memilih alternatif jawaban cukup setuju, hal ini dikarenakan responden merasa puas akan satu hal namun tidak merasa puas dengan hal yang lain. Seperti pada dimensi bukti fisik pada pernyataan nomor 3 yang mendapat nilai tanggapan responden sebesar 2,29 jumlah responden yang menjawab cukup setuju sebanyak 38 responden, hal ini dikarenakan responden merasa puas dengan tersedianya fasilitas penunjang kebutuhan seperti laboratorium namun disisi lain responden merasakan ketidakpuasan akan alat yang tersedia di dalam laboratorium karena dinilai jauh dari standar yang seharusnya. Dengan demikian unsur pada kualitas pelayanan akademik di 
Universitas Sangga Buana YPKP telah diimplementasikan dengan cukup baik, nilai rata-rata yang didapat yaitu sebesar 2,98.

Berdasarkan hasil tanggapan resonden mengenai variabel costumer relationship management dapat diketahui bahwa terdapat banyak responden yang memilih alternatif jawaban cukup setuju, hal ini dikarenakan responden merasa puas akan satu hal namun tidak merasa puas dengan hal yang lain. Seperti pada dimensi komunikasi pada pernyataan nomor 4 yang mendapat nilai tanggapan responden sebersar 2,59 jumlah responden yang menjawab cukup setuju sebanyak 31 responden, hal ini dikarenakan responden merasa bahwa dalam menyampaikan keluhan dan saran masih kurang terfasilitasi karena tidak tersedianya kotak saran atau fasilitas semacamnya meskipun ada lembaga mahasiswa atau LPM yang bisa membantu mahasiswa untuk menyampaikan keluhan dan saran yang dirasakan namun kedua lembaga tersebut belum terinformasikan dengan baik. Dengan demikian unsur costumer relationship management di Universitas Sangga Buana YPKP telah diimplementasikan dengan cukup baik, nilai rata-rata yang di dapat yaitu sebesar 3,00.

Berdasarkan tanggapan responden mengenai variabel kepuasan mahasiswa dapat diketahui bahwa terdapat banyak responden yang memilih alternatif jawaban cukup setuju, hal ini dikarenakan responden merasa puas akan satu hal namun tidak merasa puas dengan hal yang lain. Seperti pada dimensi atribut yang terkait dengan produk pada pernyataan nomor 1 yang mendapat nilai tanggapan responden sebesar 3,24 jumlah responden yang menjawab cukup setuju sebanyak 41 responden, hal ini dikarenakan responden merasa puas dengan tersedianya sumber belajar seperti buku dan jurnal di perpustakaan namun responden juga merasa kurang puas dengan keterbatasan literatur yang dibutuhkan sebagai sumber belajar karena masih terdapat banyak literatur dengan tahun terbitan lama serta tidak semua pembahasan tersedia di perpustakaan sehingga mahasiswa harus mencari sumber tambahan di perpustakaan universitas lain. Dengan demikian unsur pada kepuasan mahasiswa di Universitas Sangga Buana YPKP telah diimplementasikan dengan cukup baik, nilai rata-rata yang di dapat yaitu sebesar 3,23.

\section{Uji Validitas Kualitas Pelayanan Akademik}

Berdasarkan hasil uji validitas diketahui bahwa seluruh pernyataan tentang Kualitas Pelayanan Akademik dinyatakan valid karena nilai rhitung di atas 0,3. (Priyatno 2013:29)

\section{Uji Validitas Costumer relationship management}

Berdasarkan hasil uji validitas diketahui bahwa seluruh pernyataan tentang Costumer relationship management dinyatakan valid karena nilai rhitung di atas 0,3. (Priyatno 2013:29)

\section{Uji Validitas Kepuasan Mahasiswa}

Berdasarkan hasil uji validitas diketahui bahwa seluruh pernyataan tentang Kepuasan Mahasiswa dinyatakan valid karena nilai rhitung di atas 0,3. (Priyatno 2013:29)

\section{Uji Reliabilitas}

Berdasarkan hasil Cronbach's Alpha dapat diketahui bahwa nilai reliabilitas untuk variabel X1 yaitu sebesar 0,752 nilai reliabilitas untuk variabel X2 yaitu sebesar 0,754 dan nilai reliabilitas untuk variabel Y yaitu sebesar 0,791. Sehingga dapat disimpulkan bahwa ketiga variabel pada penelitian ini dinyatakan reliabel.

\section{Uji Normalitas}

Berdasarkan hasil uji normalitas dengan Kolmogorov Smirnov, didapatkan nilai signifikansi untuk variabel Kualitas Pelayanan Akademik yaitu 0,595 nilai signifikansi untuk variabel Costumer relationship management yaitu 0,770 dan nilai signifikansi untuk 
variabel Kepuasan Mahasiswa yaitu 0,308. Hasil uji normalitas pada ketiga variabel menunjukkan bahwa data pada penelitian ini telah berdistribusi secara normal dan model regresi telah memenuhi asumsi normalitas.

\section{Uji Asumsi Klasik}

\section{Uji Multikolinearitas}

Berdasarkan hasil uji multikolinearitas dapat diketahui bahwa nilai VIF untuk variabel X1 dan X2 sama besarnya yaitu 2,558 dengan nilai tolerance yaitu sebesar 0,391 dengan begitu data pada penelitian ini tidak ditemukan adanya multikolinearitas.

\section{Uji Autokorelasi}

Berdasarkan hasil uji autokorelasi diperoleh hasil bahwa nilai Durbin Watson sebesar 1,848 lebih besar dari batas atas (dU) $(\mathrm{k} ; \mathrm{N})$ dengan signifikansi 5\% yakni 1,705 dan kurang dari nilai 4-dU yaitu 2,295. Maka dapat disimpulkan bahwa dalam penelitian ini tidak terdapat masalah atau gejala autokorelasi.

\section{Uji Heteroskedastisitas}

Berdasarkan data grafik scatterplot dapat disimpulkan bahwa data scatterplot pada penelitian ini tidak menunjukkan adanya pola yang jelas, atau data yang tersebar secara merata. Titik menyebar di bawah angka 0 pada sumbu Y dan tidak membentuk pola tertentu yang teratur, atau acak sehingga data pada penelitian ini dapat dinyatakan bersifat homoskedastisitas.

\section{Analisis Regresi Berganda}

Berdasarkan hasil penelitian hasil analisis mengenai regresi linier berganda diketahui bahwa koefisien regresi untuk variabel X1 dan X2 masing-masing sebesar 0,233 dan 0,201 dengan konstanta sebesar 5,074.

\section{Analisis Koefien Korelasi}

1. Kualitas pelayanan akademik terhadap kepuasan mahasiswa yaitu sebesar 0,670 sehingga variabel tersebut memiliki tingkat hubungan dengan rentang kuat.

2. Costumer relationship management terhadap kepuasan mahasiswa yaitu sebesar 0,644 sehingga variabel tersebut memiliki tingkat hubungan dengan rentang kuat.

\section{Analisis Koefisien Determinasi}

Berdasarkan hasil penelitian dapat diketahui bahwa nilai koefisien determinasi sebesar 0,486 atau indeks determinasi sebesar 48,6\% dapat diartikan bahwa variasi pengaruh kualitas pelayanan akademik dan costumer relationship management terhadap kepuasan mahasiswa sebesar 48,6\% sedangkan variabel lain yang mempengaruhi kepuasan mahasiswa yang tidak dijadikan model dalam penelitian sebesar 51,4\%.

\section{Uji Hipotesis Parsial (Uji t)}

1. Terdapat pengaruh positif dan signifikan antara kualitas pelayanan akademik dengan kepuasan mahasiswa.

2. Terdapat pengaruh positif dan signifikasn antara costumer relationship management dengan kepuasan mahasiswa.

\section{Uji Hipotesis Simultan (Uji F)}

Secara simultan terdapat pengaruh positif dan signifikan antara kualitas pelayanan akademik dan costumer relationship management terhadap kepuasan mahasiswa. 


\section{SIMPULAN}

Berdasarkan tanggapan responden kualitas pelayanan akademik telah diterapkan dengan baik, namun masih terdapat beberapa aspek yang harus diperbaiki berkenaan dengan fasilitas tambahan untuk menunjang kegiatan akademik serta jadwal perkuliahan yang masih harus ditetapkan dengan baik. Terkait dengan costumer relationship management juga telah diterapkan dengan cukup baik namun responden masih merasa kurangnya tersedianya saluran komunikasi untuk menyalurkan keluhan dan saran. Secara keseluruhan tingkat kepuasan mahasiswa reguler pagi sudah cukup baik, jika kualitas pelayanan akademik dapat ditingkatkan dengan menerapkan costumer relationship management dalam kegiatan akademik maka kepuasan mahasiswa akan lebih meningkat.

\section{DAFTAR PUSTAKA}

\section{(i) Penulis tunggal (single author):}

Afifudin.2013.Dasar Dasar Manajemen.Bandung: Alfabeta.

Alma, Buchari.2018.Manajemen Pemasaran dan Pemasaran Jasa.Bandung: Alfabeta.

Daryanto.2014.Konsumen dan Pelayanan Prima.Yogyakarta: GAVA MEDIA.

Hadi, Sutrisno.2015.Metodologi Riset.

Handoko, T. Hani.2015.Manajemen Edisi 2.Yogyakarta: BPFE-Yogyakarta.

Hery.2019.Manajemen Pemasaran.Jakarta: PT Grasindo.

Kasmir.2017.Customer Service Excellent : Teori dan Praktik.Jakarta: PT Rajagrafindo Persada.

Laksana, Fajar.2008.Manajemen Pemasaran;Pendekatan Praktis.Yogyakarta: Graha Ilmu. Nasir, Moch.2016.Metode Penelitian.Bandung: Ghalia Indonesia.

Priyatno, Duwi.2014.SPSS 22 Pengolah Data Terpraktis. Yogyakarta: CV Andi Offset.

Riduwan.2014.Pengantar Statistika Sosial.Bandung: Alfabeta.

Rusydi, Mhd.2017.Customer Excellent.Yogyakarta: Gosyen Publishing.

Siregar, Syofian.2013.Statistik Parametrik Untuk Penelitian Kuantitatif.Jakarta: PT Bumi Aksara.

.2014.Statistik Parametrik Untuk Penelitian Kuantitatif.Jakarta: PT Bumi

Aksara.

Sudaryono.2016.Manajemen Pemasaran Teori dan Implementasi.Yogyakarta: CV Andi Offset.

Sugiyono.2013.Metode Penelitian Kuantitatif, Kualitatif, dan R\&D.Bandung: Alfabeta. .2014.Metode Penelitian Manajemen.Bandung: Alfabeta.

2015.Metode Penelitian Kuantitatif, Kualitatif, dan R\&D, Cetakan ke22.Bandung: Alfabeta.

Sujarweni, V. Wiratna.2014.Metodologi Penelitian: Lengkap, Praktis dan Mudah Dipahami.Yogyakarta: Pustakabarupress.

Tjiptono, Fandy.2014.Pemasaran Jasa - Prinsip, Penerapan dan Penelitian.Yogyakarta: CV Andi Offset.

(ii) multiple authors or edited work:

Abdullah, Thamrin \& Tantri, Francis.2016.Manajemen Pemasaran.Jakarta: Rajawali Pers.

Ridhotullah, Subeki \& Jauhar, Mohammad.2015.Pengantar Manajemen.Jakarta: Prestasi Pustakaraya.

Tjiptono, Fandy \& Diana, Anastasia.2016.Pemasaran Esensi dan Aplikasi.Yogyakarta: CV Andi Offset.

Tjiptono, Fandy \& Chandra, Gregorius.2016.Service, Quality and Satisfaction.Yogyakarta: CV Andi Offset.

\section{Jurnal Ilmiah:}

(i) Jurnal Versi Elektornik (Electronic - without DOI) 
Iriani, Sri Setyo.2011.Strategi Customer Relationship Marketing TerhadapLoyalitas Pelanggan. Vol.15 No.02.Universitas Negeri Surabaya.

Saidani, Basrah.Arifin, Samsul.2012.Pengaruh Kualitas Produk dan Kualitas Layanan Terhadap Kepuasan Konsumen dan Minat Beli Pada Ranch Market. Vol.3 No.01.Universitas Negeri Jakarta.

Skripsi, tesis, disertasi yang tidak dipublikasikan (Unpublished Thesis or Dissertation) (i) Print

Indriyani, Deti.2019.Pengaruh Manajemen Hubungan Pelanggan (Customer Relationship Management) dan Kualitas Jasa Terhadap Loyalitas Pelanggan Pada Cleo House di Kota Bandung.Skripsi.Universitas Sangga Buana YPKP Bandung.

Philippus, Fabriella Veronica.2018.Pengaruh Customer Relationship Management (CRM) Terhadap Tingkat Loyalitas Pelanggan Pada PT. Astra International Tbk-Toyota Sales Operation Auto 2000 Cabang Pasteur Bandung.Skripsi.Universitas Sangga Buana YPKP Bandung.

Torres, Nofiana de Jesus.2018.Pengaruh Customer Relationship Management (CRM) Terhadap Loyalitas Nasabah Pada PT. Bank Mandiri (Persero) Tbk.Skripsi.Universitas Sangga Buana YPKP Bandung. 